\title{
RichaRd W. EPPLEY's CONTRIBUTIONS TO PhytoplankTON Physiology and Biological OCEANOGRAPHY
}

\author{
By C.S. Weiler, W.M. Balch, \\ S.W. Chisholm, J.J. Cullen, \\ W.G. Harrison, P.A. Matrai, \\ J.J. McCarthy, J.R. Nelson, \\ M.J. Perry, D.G. Redalje, \\ J.H. Sharp and M.M. Sinclair
}

\begin{abstract}
RichardW. Eppley has established himself as one of the most influential biological oceanographers of this century through his contributions to the field of phytoplankton physiological ecology and his interdisciplinary approach to oceanographic processes. Dick's ability to generalize and conceptualize, to take separate threads of research and weave them into a cohesive framew'rk, has enabled him to use established techniques in novel applications, to define new approaches to old oceanographic questions, and to chart new paths. The nature and quality of his work, and particularly the breadth of his interest and expertise, places him nith H.H. Gran, G.A. Riley, J.D.H. Strickland, and others who have given the field of biological oceanography its conceptual structure. Dick's retirement in December 1989, after thirty-two years of professional service to the oceanographic community, provides an opportunity to reflect on his various accomplishments. In this article, his former Ph.D. students and postdoctoral associates briefly (and incompletely) review his contributions to oceanographic research and the oceanographic community. While Dick built on the w'ork of earlier researchers and many others were contributing to the same topics that Dick was studying, due to space constraints only those papers authored by Dick are cited. Because Dick always strove to place his work in historical context, the papers referred to below provide a key to the groundbreaking work by others.
\end{abstract}

$\mathrm{R}$ ICHARD EPPLEY received a B.A. in Botany from Washington State College and completed a Ph.D. program in plant physiology at Stanford University (Eppley. 1957) under the direction of Lawrence W. Blinks. After a brief time on the faculty at the University of Southern California (1957-63) and a stint as a research scientist with Northrop Corporation (1962-63). Dick joined the staff of the Food Chain Research Group at the Scripps Institution of Oceanography (SIO) and remained there as a Research Biologist until his retirement. He authored 111 papers between 1953 and 1989, and six more were in press or in preparation in early 1990 . The general progression of Dick's research interests reflects the breadth of perspective which he developed during his career. His early studies of algal physiology were followed by an integration of laboratory and field approaches in the study of phytoplankton biomass and growth. Field studies of primary production and nutri- ent dynamics were extended to the large-scale assessment of phytoplankton standing stock and primary production from satellite observations. Recently, the focus of much of his work has been the consideration of the role of oceanic primary production in global biogeochemical cycles.

\section{Research Interests}

Dick has made important contributions to pursuits that have become central to modern biological oceanography. These include development of techniques for estimating phytoplankton biomass and growth, studies of the diel periodicity of phytoplankton metabolism. identification of the effects of environmental factors on the physiological and chemical characteristics of phytoplankton, interpretation of chemical and physiological measurements in terms of the oceanographic processes which influence phytoplankton, and quantification of the roles of phytoplankton in microbial food webs and biogeochemical cycling.

C.S. Weiler, Dept. Biology, Whitman College. Walla Walla, WA 99362; W.M. Balch and P.A. Matrai. RSMAS, University of Miami. 4600 Rickenbacker Cswy.. Miami. FL 33149: S.W. Chisholm. Dept. Civil Engineering. Ralph Parsons Lab.. Bldg. 48. Massachusetts Inst. of Technology, Cambridge. MA 02139; J.J. Cullen, Bigelow Laboratory, McKown Point. W. Boothbay Harbor, ME 04575; W. G. Harrison and M.M. Sinclair. Bedford Inst. of Oceanography, Dartmouth. NS B2Y 4A2, Canada: J.J. McCarthy. Museum of Comparative Zoology. Harvard University, Cambridge, MA 02138; J.R. Nelson, Skidaway Inst. of Oceanography, P.O. Box 13687, Savannah, GA 31406; M.J. Perry. School of Oceanography, University of Washington. Seattle. WA 98195; D.G. Redalje. Center for Marine Science. Univ. of Southern Mississippi. Stennis Space Center. MS 39529; J.H. Sharp, College of Marine Studies, University of Delaware, Lewes. DE 19958. 
Measurement of Phytoplankton Biomass and

Rate Processes in the Sea

To describe the dynamics of planktonic ecosystems, growth rates of phytoplankton must be specified. It is very difficult to measure specific growth rates of phytoplankton in nature because both primary production and phytoplankton standing stock (particulate carbon content) must be assessed simultaneously to estimate growth rate (Eppley, 1980). Measurement of primary production presents a host of challenges, and determination of standing stock is confounded by detrital and heterotrophic contributions to particulate organic carbon as well as the inadequacy of chlorophyll concentration as a measure of the standing stock of phytoplankton (Eppley et al., 1977). Dick grappled with these problems throughout his career, with considerable success.

In the laboratory, early studies examined the relationships between phytoplankton growth and various parameters, including cell surface area, cell volume, pigment content, chemical composition, temperature and light intensity (Eppley and Dyer, 1965; Eppley and Sloan, 1966). An early field approach involved incubating natural samples with ${ }^{14} \mathrm{C}$ and assessing carbon assimilation after twenty-four and forty-eight hours, enabling back-calculation of the initial standing stock (Eppley, 1968; Eppley and Strickland, 1968). Dick recognized the pitfalls of containing phytoplankton under artificial conditions and searched for "an instantaneous method not confounded by the complexities of long incubation." This led to work on a variety of methodologies in his laboratory, including the determination of growth rate from the frequency of dividing cells (Weiler and Eppley, 1979). The development of species-specific techniques continues as a major objective in many laboratories.

Dick's often cited review of temperature and phytoplankton growth (1972) is a good example of how he integrated laboratory studies of phytoplankton physiology into field work and the mainstream of biological oceanography. Reviewing much of the available literature, Dick derived a curve describing the expected maximum specific growth rates of phytoplankton in the temperature range of $2^{\circ}$ to $40^{\circ} \mathrm{C}$. The observation that estimates of phytoplankton growth rates in the field rarely approached the expected maximum provided the starting point for discussions of the importance of estimating phytoplankton specific growth rates in the field, the problems in doing so, and the relationship of growth at different temperatures to photosynthetic capacity.

By 1979, many of the early reports in the literature regarding rates of production and growth in the open oceans were being questioned, along with the concepts and techniques used to describe and determine phytoplankton dynamics and food web structure in the ocean (Eppley, 1981). In response, Dick assembled a team of researchers who became the investigators of the Plankton Rate Processes in Oligotrophic Oceans (PRPOOS) program (Eppley, 1982). This interdisciplinary program incorporated new concepts of the microbial loop food web into the study of open ocean food webs and involved a variety of new and innovative techniques to evaluate planktonic rate processes. Diel Periodicity

Dick's work on diel periodicity provides an example of his efforts to bridge the gap between plant physiology and oceanography. While others before him had shown that there was periodicity in cell division and photosynthesis in the sea and that cultures of phytoplankton could be synchronized by light/dark cycles, the impact of diel processes on short-term sampling programs and on plankton physiology and ecology were not generally appreciated. Dick was the first to drive home the message that all physiological processes in photosynthetic organisms in the oceans are coupled in some way to the entraining photocycle. $\mathrm{He}$ also demonstrated that diel patterns of vertical migration had implications for nutrient uptake patterns and species succession (see below). Dick's laboratory experiments were always designed with attention to "real world" implications, and they were intended to be interpreted in an oceanographic context (Eppley and Coatsworth, 1966; Eppley et al., 1967, 1968 and 1970; Chisholm et al., 1978; Weiler and Eppley, 1979). In a complementary manner, his field experiments were designed with unusual attentiveness to the proper time and space scales for meaningful physiological measurements (Eppley et al., 1971; Eppley et al., 1973; Eppley and Sharp, 1975; Eppley et al., 1979). His work, and the work it inspired by others, demonstrated that cells respond to the photocycle in complex but predictable ways, and that these diel periodicities impose significant and measurable diel signals on physiological, metabolic and ecological processes within the water column.

Nutrients

For decades, Dick studied the effect of nutrients on algal growth and physiology to understand effects of nutrient supply on phytoplankton dynamics and to discern the role of phytoplankton in the ocean's nitrogen cycle. Experimental systems included nutrient-limited cultures, continuous cultures, large shipboard incubations, and other experimental manipulations on land and at sea. For instance, Dick and his colleagues used the "Deep Tank" (Strickland et al., 1969), a 3-m diameter by $10-\mathrm{m}$ high container at SIO, to study the growth and chemical composition of phytoplankton cultures on a previously unattainable scale, "between breakers and bays." Among other things, this tank was used to describe the vertical migration of dinoflagellates (Eppley et al., 1968). Later, Dick demonstrated a principal adaptive advantage of diel vertical migration: a red-tide dinoflagellate could grow at the expense of nitrate taken up during nocturnal descent from nutrient-depleted surface layers (Eppley and Harrison, 1974). $\mathrm{He}$ also led several studies which examined the growth of phytoplankton in nutrient-enhanced, shipboard cultures (Eppley et al., 1971), and considered the effects of nutrient concentration (Eppley et al., 1973) and the length of incubation (Eppley and Sharp, 1975). Another study examined the relationship between microscopically determined phytoplankton carbon content with easily measurable field parameters, such as

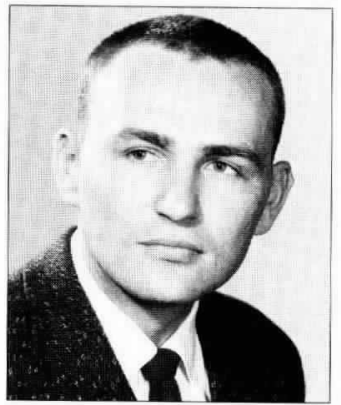

Richard W. Eppley

in 1960, shortly

after becoming an

Assistant Professor

at the University of

Southern California. 


\section{$D_{\text {ick's breadth of }}$}

understanding and

wealth of ideas have

stimulated a diverse

list of research

activities. particulate organic carbon (POC), ATP, light intensity, phosphate concentrations, pigment concentrations and the POC:Chl-a ratio (Eppley et al., 1977). Comparison of the results of field studies with observations obtained in controlled laboratory experiments indicated that marine phytoplankton dynamics were similar to what had been described in nutrient-limited continuous cultures, particularly for oligotrophic phytoplankton populations (Eppley, 1980).

Dick contributed substantially to an understanding of the relationships between nitrogen-limited growth and the kinetics of nitrogen uptake and assimilation (Eppley et al., 1968; Eppley et al., 1969; Eppley and Thomas, 1969; Eppley etal., 1970; Eppley et al. 1971; Eppley et al., 1973; Eppley and Renger, 1974; Sharp et al., 1980). The Eppley and Thomas (1969) paper was reprinted in a collection of papers on aquatic ecology, and the Eppley et al. (1969) paper was a "Current Contents Citation Classic" in 1979. The Eppley et al. (1969) work was stimulated after the importance of nutrient availability in regulating primary production in the sea and the physiological enzymatic basis of nutrient uptake was well established, to address whether species-specific kinetic parameters for nitrate and ammonium uptake could help to explain the spatial and temporal occurrence of phytoplankton populations in the sea. They examined uptake kinetics for seventeen phytoplankton species and identified a pattern indicating that there is indeed ecological significance in the species-specific kinetic parameters for nutrient uptake. This paper helped to stimulate a more quantitative approach to the study of nutrient regulation in the sea.

Dick's awareness of the limitations of lab cultures in simulating the complexities of the natural environment was at least partly responsible for his studies using nitrogen tracers in the field. Much of our current understanding about the cycling of nitrogen through the plankton food web of the open ocean can be traced to Dick's North Pacific Gyre studies of the early 1970s. The same can be said for his work in coastal waters, centered around the long-term Southern California Bight Study (SCBS) (Eppley, 1986). Dick's breadth of understanding and wealth of ideas have stimulated a diverse list of research activities on nitrogen cycling pursued by his students and postdoctoral associates. Comparison of the results of field studies with observations obtained in controlled laboratory experiments indicated that marine phytoplankton dynamics were similar to what had been described in nutrient-limited continuous cultures, particularly for oligotrophic phytoplankton populations (Eppley, 1980).

Phytoplankton and Physical Processes

The coupling between biological and physical processes is the subject of much research today. Dick has long held an interest in the relationship between phytoplankton and physical mixing. Twenty-five years ago, he and a student, J.E. Brooks, submitted a paper to Science entitled "Residence time and depth of phytoplankton communities: Inferences from photosynthesis characteristics." They estimated rates of vertical mixing from the differentiation with depth of phytoplankton photosynthetic responses. The manuscript was definitely ahead of its time and was not accepted for publication, but the utility of Dick's approach has since been validated by others. In 1979, Dick related biology to physics by estimating the coefficient of vertical eddy diffusivity from measurements of nitrate uptake and the vertical gradient of nitrate. This technique has successfully been refined by others and applied in a rigorous fashion. Dick's interest in vertical mixing and his recognition that episodic events may be important led him to design in 1978 an interdisciplinary field experiment which examined physical-biological coupling as a function of scale (Cullen et al., 1983). Observations from this study suggested that a mixing event associated with shear instabilities generated by internal waves caused the transport of nitrate into the surface layer. Such intermittent injections of nutrients have since been considered by others to be important to planktonic dynamics and biogeochemical cycling. More recently, Dick applied the chemiluminescent technique forlow-level detection of nitrate and nitrate and observed that a nanomolar increase in surface layer nitrate concentration following a short wind event was consumed in a single day (Eppley and Renger, 1988), a work which emphasized the importance of understanding the time and space variability of new and regenerated production in the sea.

Dick examined physical-biological coupling on a larger scale, too. Differences in productivity were successfully correlated with sea-surface temperature anomalies at the Scripps Pier (Smith and Eppley, 1982), demonstrating that large-scale hydrographic perturbations might have significant and predictable effects on primary productivity even though the proximate influences on physical processes are quite subtle. Subsequently, it has been shown by others that basin-wide events have profound consequences at the ecosystem level.

\section{Toward a Global Perspective}

Among his publications on the nitrogen cycle in the ocean, one that has generated widespread interest and has contributed significantly towards improved understanding of the linkages between biological, physical, chemical and geological processes in the sea is that of Eppley and Peterson (1979). Building on the earlier concept of new versus recycled production presented by Dugdale and Goering, Dick's paper provided the first global perspective on the segregation of production sources and the relationship between production and the export of biogenic material to the deep ocean. For the first time, the regulation of key planktonic processes was put into a context that attracted the attention of geochemists, physicists and geologists. The concept of "new production" is now discussed regularly by scientists in all these fields. There is no doubt that this paper had a tremendous impact on the development of our scientific understanding of the larger role of biota in ocean processes during the last decade (Eppley, 1989). Importantly, it has also provided the conceptual underpinning and coordinated research on biogeochemical cycles linking the domains of ocean, atmosphere and solid earth, and it lies at the heart of the rationale for global scale studies like those now being 
planned and implemented under the aegis of the Joint Global Ocean Flux Study.

The large-scale biogeochemical perspective of the Eppley and Peterson paper was also reflected in papers dealing with long time-series and remote sensing of chlorophyll and primary production. Smith and Eppley (1982) demonstrated the use of the long-term Scripps Pier Temperature Record for hindcasting phytoplankton productivity, zooplankton abundance and anchovy biomass. Eppley et al. (1985) showed that the ratio between satellite-derived chlorophyll and integrated photosynthesis was not constant but varied both regionally and seasonally. More important, they derived an algorithm which used the Scripps pier temperature anomaly, day-length and satellite-derived chlorophyll to estimate primary production. Regional and seasonal variability in the ratio of satellite-derived chlorophyll and integrated photosynthesis was noted. This approach was further extended by Eppley et al. (1987) in a study which detailed how physical mixing and photoadaptation could affect the ratio of satellitederived chlorophyll to integrated primary production. Their new algorithm, which included the physiological parameter $\mathrm{P}_{\text {max }}$ (maximum rate of chlorophyll-specific photosynthesis), accounted for $70 \%$ of the variance in primary production within the Eastropac data set. It is interesting that space technology influenced Dick's research both early and late in his career. In the 1950s and $1960 \mathrm{~s}$, research on culturing phytoplankton was stimulated by a potential application in life support systems for satellites, whereas in the 1970s and 1980s, observations from satellites stimulated more research into the activities in phytoplankton.

\section{Community Service}

Service to the broad oceanographic community has always been important to Dick, and his contributions to institutions, societies and agencies are too numerous to list. Highlights include: Rotator, U.S. Atomic Energy Commission, Biomedical and Environmental Research Division (1972-73); President of American Society of Limnology and Oceanography (ASLO) (1981-82); National Science Foundation (NSF) Executive Advisory Committee, Ocean Sciences Division (1981-1985); Global Ocean Flux Steering/Executive Committee (1985-1989); and participation in twenty-six working groups and workshops. Dick is a member of Phi Beta Kappa. He was awarded the Darbaker Prize in Phycology by the Botanical Society of America in 1971 and the G. Evelyn Hutchinson Medal by ASLO in 1984. In 1990, he was elected a Fellow of the American Geophysical Union. Despite his heavy research obligations and other commitments, he still found time to review an average of forty manuscripts per year and remain a regular reviewer of proposals for NSF, the Department of Energy and Sea Grant.

Attention is increasingly focused on student education and the need to both inspire and train the next generation. It therefore seems particularly appropriate to mention Dick's contributions as an educator. Although he held a research rather than a faculty position, he excelled as an educator. He served as major advisor to eight Ph.D. students (J.J. McCarthy, 1971; M.J.

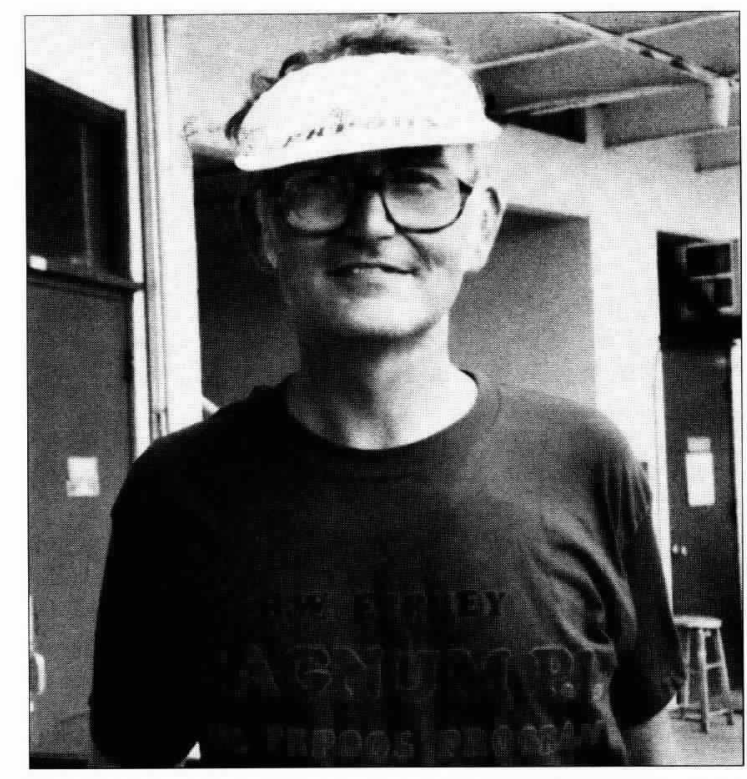

Dick Eppley as coordinator of the PRPOOS (Plankton Rate Processes in Oligotrophic Oceans) program (1982). The main objectives of PRPOOS were to determine the rate of primary production in the central oligotrophic oceans and to reconcile historical measurements $\left({ }^{14} \mathrm{C}\right)$ method with newer methods.

Perry, 1974; M.M. Sinclair, 1977; C.S. Weiler, 1978; J.J. Cullen, 1980; W.M. Balch, 1985; J.R. Nelson, 1986; and P.A. Matrai, 1988) and trained four postdoctoral researchers (J.H. Sharp, 1971-73; S.W. Chisholm, 1974-76; W.G. Harrison, 1974-76; and D.G. Redalje, 1980-82). His teaching activities benefited scores of students at SIO (Senior Adjunct Lecturer, SIO, 1969-1989) and elsewhere (UNESCO Plankton Course at Mar del Plata, Argentina, 1965; courses at Friday Harbor Laboratories, 1972, 1980, 1989; lectures as a Visiting Scholar at Woods Hole Oceanographic Institution, 1979; and Visiting Professor at the Institut für Meereskunde, Kiel University, 1985). In addition to formal advising and teaching, Dick encouraged, guided and supported many other students at Scripps and elsewhere. Furthermore, because he consistently reported his work in historical context, his papers remain a particularly significant contribution to the oceanographic community for their educational as well as informational value.

Dick's openness and enthusiasm, his collaborative research approach, the support and encouragement offered by both him and his long-time research associate Ed Renger, and the wonderful parties thrown by Dick and Jean at their home, made his laboratory a particularly pleasant work environment. Those of us who benefited from his tutelage during stays in his laboratory or through other associations are a particularly fortunate lot. Dick, you have taught us many important lessons about nature as well as the proper methods of science and the manners of a true scientist. The example you set is a constant inspiration to all who have come to know you. We wish you smooth sailing and good hiking! 
References

Chisholm, S.W., F. Azam and R.W. Eppley, 1978: Silicic acid incorporation in marine diatoms on light:dark cycles: Use as an assay for phased cell division. Limnol. Oceanogr.. $23,518-529$.

Cullen. J.J.. E. Stewart, E. Renger, R.W. Eppley and C.C. Winant, 1983: Vertical motion of the thermocline, nitracline and chlorophyll maximum layers in relation to currents on the Southern California Shelf. J, Mar. Res., 41, 239-262.

Eppley, R.W.. 1957: Sodium and potassium regulation by a marine red alga, Porphyra perforata. Ph.D. Dissertation, Stanford University. $130 \mathrm{pp}$.

1968: An incubation method for estimating the carbon content of phytoplankton in natural samples. Limnol. Oceanogr., 13.574-582.

1972: Temperature and phytoplankton growth in the sea. Fish. Bull., 70, 1063-1085.

1980: Estimating phytoplankton growth rates in the central oligotrophic oceans. In: Primary Productivity in the Sea. P. Falkowski, ed., Plenum Press. New York, 321 242.

1981: Relations between nutrient assimilation and growth in phytoplankton with a brief review of estimates of growth rate in the ocean. In: Physiological Bases of Phytoplankton Ecology. T. Platt, ed.. Can.Bull.Fish.Aquat. Sci., 210. 251-263.

1982: The PRPOOS Program: A study of plankton rate processes in oligotrophic oceans. EOS, 63, 522. ed., 1986: Plankton Dinamics of the Sotuthern California Bight. Lecture Notes on Coastal and Estuarine Studies. Springer-Verlag. Berlin and New York, $373 \mathrm{pp}$.

1989: New Production: History, methods, problems. In: Productivity of the Oceun: Present and Past. Report of the Dahlem Workshop, Berlin, 1988. W.H. Berger, V.S Smetacek and G. Wefer, eds., John Wiley \& Sons, 85-97. and D.L. Dycr. 1965: Predicting production in lightlimited continuous cultures of algae. Appl. Microbol., I3, 833-837.

and J.L. Coatsworth. 1966: Culture of the marine phytoplankter, Dunaliella tertiolecta, with light-dark cycles. Archiv für Mikrobiologie, 56. 305-323.

and P.R. Sloan, 1966: Growth rates of marine phytoplankton: Correlation with light absorption by cell chlorophyll-a. Physiol. Plant., 19, 47-59.

R.W. Holmes and E. Paasche, 1967: Periodicity in cell division and physiological behavior of Ditylum brightwellii, a marine planktonic diatom, during growth in light-dark cycles. Archiv für Mikrobiologie, 56, 305-323.

O. Holm-Hansen and J.D.H. Strickland, 1968: Some observations on the vertical migration of dinoflagellates. J. Phycol., 4, 333-340.

and J.D.H. Strickland, 1968: Kinetics of marine phytoplankton growth. In: Advances in the Microbiology of the Sea. M.R. Droop and E.J.F. Wood, eds., Academic Press. New York. 23-62.

and W.H. Thomas, 1969: Comparison of half-saturation constants for growth and nitrate uptake of marine phytoplankton. J. Phycol., 5, 375-379. Reprinted in: R.F. Ford and W.E. Hazen. 1972: Readings in Aquatic Ecology W.B. Saunders Co., pp. 19-23.

J.N. Rogers and J.J. McCarthy, 1969: Half-saturation constants for uptake of nitrate and ammonium by marine phytoplankton. Limnol. Oceanogr., 14.912-920.

J.N. Rogers. J.J. McCarthy and A. Sournia, 1970: Light/ dark periodicity in nitrogen assimilation of the marine phytoplankters. Skeletonema costatum and Coccolithus huxleyi in N-limited chemostat culture. J. Phycol., 7, 150154.
,A.F.Carlucci, O. Holm-Hansen, D. Kiefer.J.J. McCarthy, E. Venrick and P.M. Williams, 1971: Phytoplankton growth and composition in shipboard cultures supplied with nitrate, ammonium, or urea as the nitrogen source. Limnol. Oceanogr., 16, 741-751.

.E.H. Renger, E.L. Venrick and M.M. Mullin, 1973: A study of plankton dynamics and nutrient cycling in the central gyre of the North Pacific Ocean. Limnol. Oceanogr., 18, 534-551.

and W.G. Harrison. 1974: Physiological ecology of Gomyaulax polyedra. a red water dinoflagellate of Southern California. In: Proc. Ist. Int. Conf. on Toxic Dinoflagellate Blooms, Nov. 1974, Wakefield, Mass. U.R. Le Cicero, ed., pp. 11-22.

and E.H. Renger, 1974: Nitrogen assimilation of an oceanic diatom in Nitrogen-limited continuous culture. $J$. Phycol. 10. 15-23.

and J.H. Sharp, 1975: Photosynthetic measurements in the central North Pacific: The dark loss of carbon in 24-h incubations. Limnol. Oceanogr.. 20.981-987.

W.G. Harrison, S.W. Chisholm and E. Stewart, 1977: Particulate organic matter in surface waters off Southern California and its relationship to phytoplankton. J. Mar. Res. 35, 671-696.

and B.J. Peterson, 1979: Particulate organic matter flux and planktonic new production in the deep ocean. Nature. 282, 677-680.

E.H. Renger and W.G. Harrison. 1979: Nitrate and phytoplankton production in Southern California coastal waters. Limol. Oceanogr., 27, 483-494.

E. Stewart. M.R. Abbott and U. Heyman, 1985: Estimating ocean primary production from satellite chlorophyll. Introduction to regional differences and statistics for the Southern California Bight. J. Plank. Res.. 7. 57-70.

E.F. Stewart, M.R. Abbott and R.W. Owen. 1987: Estimating ocean production from satellite-derived chlorophyll: Insights from the Eastropac data set. In: Proceedings International Symposium on Equatorial Vertical Motion. Paris, 6-10 May 1985. Oceanologica Acta, pp. 109-113.

and E.H. Renger. 1988: Nanomolar increase in surface layer nitrate concentration following a small wind event. Deep-Sea Res., 35, 1119-1125.

Sharp, J.H., M.J. Perry, E.H. Renger and R.W. Eppley, 1980: Phytoplankton rate processes in the oligotrophic waters of the central North Pacific Ocean. J. Plankton Res., 2. 335353.

Smith. P.E. and R.W. Eppley, 1982: Primary production and the anchovy population in the Southern California Bight: Comparison of time series. Limnol. Oceanogr., 27, 1-17.

Strickland, J.D.H., O. Holm-Hansen. R.W. Eppley and R.J. Linn, 1969: The use of a deeptank in plankton ecology. I. Studies of the growth and composition of phytoplankton crops at low nutrient levels. Limnol. Oceanogr., 14, 23-34.

Weiler.C.S. and R.W. Eppley, 1979: Temporal pattern of division in the dinoflagellate genus Cratium and its application to the determination of growth rate. J. Exp. Mar. Biol. Ecol, 39. $1-24.4$

For a complete list of Richard Eppley's publications to date, write to Ms. Doris Osbourn, Scripps Institution of Oceanography, A012-F, La Jolla, CA 92093. 